\title{
Syntheses, crystal structures, and resistivities of the two new ternary uranium selenides, $\mathrm{Er}_{3} \mathrm{USe}_{8}$ and $\mathrm{Yb}_{3} \mathrm{USe}_{8}$
}

\author{
Jai Prakasha, Adel Mesbah ${ }^{\mathrm{a}, \mathrm{b}}$, Jessica C. Beard ${ }^{\mathrm{a}}$, Christos D. Malliakas ${ }^{\mathrm{a}}$, and James A. \\ Ibers $^{\mathrm{a}, *}$
}

aDepartment of Chemistry, Northwestern University, 2145 Sheridan Road, Evanston, IL 60208-3113, United States.

bICSM, UMR 5257 CEA / CNRS / UM2 / ENSCM, Site de Marcoule - Bât. 426, BP 17171, 30207 Bagnols-surCèze cedex, France.

Keywords: lanthanide uranium selenides; crystal structure; resistivity

\begin{abstract}
Two new ternary lanthanide ( $\mathrm{Ln}$ ) uranium selenides, $\mathrm{Er}_{3} \mathrm{USe}_{8}$ and $\mathrm{Yb}_{3} \mathrm{USe}_{8}$, were synthesized at $1198 \mathrm{~K}$ using $\mathrm{NaI}$ as a flux. Single-crystal X-ray studies show these two compounds to be isostructural and to crystallize in space group $D_{2}^{1} h-P b c m$ of the orthorhombic crystal system. The Ln and $\mathrm{U}$ atoms are disordered on the same crystallographic site in these crystal structures. Each $\mathrm{Ln} / \mathrm{U}$ atom is coordinated to eight Se atoms in a bicapped trigonal prism, and sharing of these $(\mathrm{Ln} / \mathrm{U}) \mathrm{Se}_{8}$ units creates a three-dimensional network. Se2 atoms are connected to each other to form infinite one-dimensional chains along the $c$ axis. In these chains, the two Se atoms are separated by about $2.74 \AA$, a distance intermediate to those of a Se-Se single bond and a van der Waals interaction. Temperature-dependent resistivity measurements show that $\mathrm{Er}_{3} \mathrm{USe}_{8}$ and $\mathrm{Yb}_{3} \mathrm{USe}_{8}$ are semiconductors with activation energies of $0.08(1)$ and $0.17(1) \mathrm{eV}$, respectively.
\end{abstract}

*Corresponding author.

E-mail address: ibers@ chem.northwestern.edu (J.A.Ibers)

(C) 2015. This manuscript version is made available under the Elsevier user license http://www.elsevier.com/open-access/userlicense/1.0/ 


\section{Introduction}

One of the major challenges in the processing of nuclear waste is the separation of radioactive $\mathrm{An}^{3+}$ species from $\mathrm{Ln}^{3+}$ species ( $\mathrm{An}=$ actinide; $\mathrm{Ln}=$ lanthanide) because of their similar ionic sizes and chemistry. To develop an effective method for separation of these species, research has focused on their solution chemistry [1-3]. However, the chemistry of actinides and lanthanides in solid-state compounds is less studied and somewhat neglected as compared with their solution chemistry. The crystal structures of most of the extended solid-state compounds either show disorder between Ln and An or are an ordered variant of their known binary phases. Examples of compounds whose structures show $\mathrm{Ln} / \mathrm{An}$ disorder include $(\mathrm{Ln} / \mathrm{Th}) \mathrm{O}_{2}(\mathrm{Ln}=\mathrm{La}$, Nd, Sm, Gd) [4], (Ln/U)N (Ln = La-Nd, Sm, Gd, Dy, Er) [5], (Ln/U) ${ }_{3} \mathrm{Q}_{4}(\mathrm{Ln}=\mathrm{La}, \mathrm{Ce}, \mathrm{Pr} ; \mathrm{Q}=\mathrm{S}$, $\mathrm{Se}, \mathrm{Te})[6],(\mathrm{Ln} / \mathrm{U}) \mathrm{S}(\mathrm{Ln}=\mathrm{Pr}, \mathrm{Nd})$ [7], and (Ln/U)Te $3(\mathrm{Ln}=\mathrm{La}-\mathrm{Nd}, \mathrm{Sm}, \mathrm{Gd}-\mathrm{Lu})$ [8,9]. Examples of compounds in whose structures Ln and An atoms occupy different crystallographic sites are $\left(\mathrm{Ln}^{3+}\right)_{2} \mathrm{An}^{4+} \mathrm{Q}_{5}(\mathrm{Ln}=\mathrm{La}-\mathrm{Gd}, \mathrm{Q}=\mathrm{S}, \mathrm{Se})[10-12]$ and $\left(\mathrm{Ln}^{3+}\right)_{6}\left(\mathrm{U}^{6+}\right) \mathrm{O}_{12}(\mathrm{Ln}=\mathrm{La}, \mathrm{Lu})$ [13]; these are ordered variants of the structures of the binary compounds $\mathrm{U}_{3} \mathrm{~S}_{5}$ [14] and $\mathrm{Ln}_{7} \mathrm{O}_{12}$ [15], respectively.

There are only a few structures of solid-state compounds where An and Ln atoms occupy different crystallographic sites in new structure types as well. These include $\mathrm{Cs}_{11} \mathrm{Eu}_{4}\left(\mathrm{UO}_{2}\right)_{2}\left(\mathrm{P}_{2} \mathrm{O}_{7}\right)_{6}\left(\mathrm{PO}_{4}\right) \quad[16], \quad \mathrm{Nd}\left[\left(\mathrm{UO}_{2}\right)_{3} \mathrm{O}(\mathrm{OH})\left(\mathrm{PO}_{4}\right)_{2}\right] \bullet 6 \mathrm{H}_{2} \mathrm{O} \quad$ [17], $\mathrm{H}_{2}\left[\mathrm{Nd}_{2}\left(\mathrm{H}_{2} \mathrm{O}\right)_{12} \mathrm{UMo}_{12} \mathrm{O}_{42}\right] \cdot 12 \mathrm{H}_{2} \mathrm{O}$ [18], $\mathrm{Ln}_{3} \mathrm{UO}_{6} \mathrm{Cl}_{3}$ ( $\left.\mathrm{Ln}=\mathrm{La}, \mathrm{Pr}, \mathrm{Nd}\right)$ [19], EuUI 6 [20], and $\mathrm{La}_{2} \mathrm{U}_{2} \mathrm{Se}_{9}$ [21], the last being the only example of an $\mathrm{Ln} / \mathrm{An}$ chalcogenide.

In order to extend the solid-state chemistry of Ln/An compounds we have carried out exploratory syntheses in the $\mathrm{Ln} / \mathrm{U} / \mathrm{Se}$ system. Our efforts have led to discovery of the two new isostructural compounds $\mathrm{Er}_{3} \mathrm{USe}_{8}$ and $\mathrm{Yb}_{3} \mathrm{USe}_{8}$. Though the structure of these compounds shows $\mathrm{Ln} / \mathrm{U}$ disorder it is not a variant of a known binary structure. Here we present the syntheses, crystal structures, and electrical properties of $\mathrm{Er}_{3} \mathrm{USe}_{8}$ and $\mathrm{Yb}_{3} \mathrm{USe}_{8}$.

\section{Experimental}

\subsection{Syntheses}


Caution! Depleted $\mathrm{U}$ is an $\alpha$-emitting radioisotope and as such is considered a health risk. Its use requires appropriate infrastructure and personnel trained in the handling of radioactive materials.

The starting materials, Yb (Alfa, $99.9 \%$ ), Er (Alfa, $99.9 \%)$, NaI (Alfa, 99.5\%), and Se (Cerac, $99.999 \%$ ) were used as obtained. Depleted U powder was obtained by hydridization and decomposition of $U$ turnings (IBI Labs) in a modification [22] of a previous literature method [23]. Reactions were performed in sealed $6 \mathrm{~mm}$ carbon-coated fused-silica tubes. Chemical manipulations were performed inside an Ar-filled dry box. The reactants were weighed and transferred into tubes that were then evacuated to $10^{-4}$ Torr, flame sealed, and heated in a computer-controlled furnace.

Semi-quantitative EDX analyses of the products of the reactions were obtained with the use of a Hitachi S-3400 SEM microscope. The EDX analyses of the desired products were repeated from crystal to crystal and the results were $\mathrm{Ln}: \mathrm{U}=3: 1$ with a 5\% deviation. Unit cells of several of these $\mathrm{Ln}_{3} \mathrm{USe}_{8}$ crystals that had been attached to carbon tape for EDX analysis did not show significant variations in cell constants. In each instance from among those crystals one was selected for the X-ray structure determination.

Synthesis of $\mathrm{Er}_{3} \mathrm{USe}_{8}$. Crystals of $\mathrm{Er}_{3} \mathrm{USe}_{8}$ were obtained by the reaction of elements $\mathrm{Er}$ (14.0 mg, $0.0837 \mathrm{mmol}), \mathrm{U}(10 \mathrm{mg}, 0.0420 \mathrm{mmol}), \mathrm{Se}(33.2 \mathrm{mg}, 0.4205 \mathrm{mmol})$, with excess NaI flux $(58.0 \mathrm{mg}, 0.387 \mathrm{mmol})$. The reaction mixture was heated to $1053 \mathrm{~K}$ at $33 \mathrm{~K} / \mathrm{h}$, held there for $24 \mathrm{~h}$, heated to $1198 \mathrm{~K}$ at $6 \mathrm{~K} / \mathrm{h}$, held there for $99 \mathrm{~h}$, cooled to $998 \mathrm{~K}$ at $2 \mathrm{~K} / \mathrm{h}$, to $598 \mathrm{~K}$ at $4 \mathrm{~K} / \mathrm{h}$, and then to $298 \mathrm{~K}$ at $12.5 \mathrm{~K} / \mathrm{h}$. The reaction product was washed with acetone to remove the NaI flux and then dried under vacuum for $2 \mathrm{~h}$. The washed product contained black plates and needles of $\mathrm{Er}_{3} \mathrm{USe}_{8}(\mathrm{Er}: \mathrm{U}: \mathrm{Se} \approx 3: 1: 8), \mathrm{Er}_{2} \mathrm{Se}_{3}$ [24] (Er:Se $\left.\approx 2: 3\right)$, and black plates of UOSe (U:Se $\approx 1: 1)[25]$.

Synthesis of $\mathrm{Yb}_{3} \mathrm{USe}_{8}$. Crystals of $\mathrm{Yb}_{3} \mathrm{USe}_{8}$ were obtained by the reaction of elements $\mathrm{Yb}$ (14.5 mg, $0.0838 \mathrm{mmol}), \mathrm{U}$ (10 mg, $0.0420 \mathrm{mmol})$, Se (33.2 mg, $0.4205 \mathrm{mmol})$, with excess NaI flux $(57.7 \mathrm{mg}, 0.385 \mathrm{mmol})$. The same procedures as for $\mathrm{Er}_{3} \mathrm{USe}_{8}$ resulted in a washed product 
that contained black plates and needles of $\mathrm{Yb}_{3} \mathrm{USe} \mathrm{s}_{8}(\mathrm{Yb}: \mathrm{U}: \mathrm{Se} \approx 3: 1: 8)$ along with $\mathrm{Yb}_{2} \mathrm{Se}_{3}$ [26] and UOSe [25].

\subsection{Structure determinations}

The crystal structures of $\mathrm{Er}_{3} \mathrm{USe}_{8}$ and $\mathrm{Yb}_{3} \mathrm{USe}_{8}$ were determined from single-crystal $\mathrm{X}$ ray diffraction data collected with the use of graphite-monochromatized $\operatorname{MoK} \alpha$ radiation $(\lambda=$ $0.71073 \AA$ ) at $100(2) \mathrm{K}$ on a Bruker APEX2 diffractometer [27]. The algorithm COSMO implemented in the program APEX2 was used to establish the data collection strategy with a series of $0.3^{\circ}$ scans in $\omega$ and $\varphi$. The exposure time was $15 \mathrm{sec} /$ frame and the crystal-to-detector distance was $50 \mathrm{~mm}$ for both compounds. The collection of intensity data as well as cell refinement and data reduction were carried out with the use of the program APEX2 [27]. Faceindexed absorption, incident beam, and decay corrections were performed with the use of the program SADABS [28]. Precession images of the data sets provided no evidence for supercells or modulations. The crystal structures of these two compounds were solved and refined with the use of the SHELX-14 algorithms of the SHELXL program package [28,29]. A disorder between Ln and $U$ at the (4d) crystallographic site was observed for both compounds. Determination of chemical composition from X-ray diffraction data is fraught with difficulties under the best of circumstances. In the present instance a determination of the Ln: $U$ ratio by refinement of their occupancies at this common site is out of the question because the very small cell volume precludes there being a sufficient number of low-angle reflections sensitive to the differences in the atomic scattering factors of the respective elements. Accordingly, the occupancies of Ln and $\mathrm{U}$ were fixed at 3:1 as found by EDX measurements. A disorder between $\mathrm{Ln}$ and $\mathrm{U}$ is not surprising as their ionic radii in eight-fold coordination environment are essentially equal: $\mathrm{Er}^{3+}$ $(1.004 \AA), \mathrm{Yb}^{3+}(0.985 \AA)$, and $\mathrm{U}^{4+}(1.00 \AA)$ [30].

\subsection{Resistivity measurements}

Four-probe temperature-dependent resistivity data for $\mathrm{Er}_{3} \mathrm{USe}_{8}$ and $\mathrm{Yb}_{3} \mathrm{USe}_{8}$ were collected using a home-made resistivity apparatus equipped with a Keithley 2182 nanovoltmeter, a Keithley 236 source measure unit, and a high-temperature vacuum chamber controlled by a K- 
20 MMR system. An $I-V$ curve from $1 \times 10^{-8}$ to $-1 \times 10^{-8}$ A with a step of $4 \times 10^{-9}$ A was measured for each temperature point (from 300 to $500 \mathrm{~K}$ ) and resistance was calculated from the slope of the plot. Data acquisition was controlled by custom-written software. Graphite paint (PELCO Isopropanol based graphite paint) was used for electrical contacts with copper wire of $0.025 \mathrm{~mm}$ thickness (Omega). The DC current was applied along an arbitrary direction on a single crystal with dimensions $0.16 \times 0.05 \times 0.05 \mathrm{~mm}$ and $0.20 \times 0.09 \times 0.07 \mathrm{~mm}$ for $\mathrm{Er}_{3} \mathrm{USe}_{8}$ and $\mathrm{Yb}_{3} \mathrm{USe}_{3}$, respectively.

\section{Results}

\subsection{Syntheses}

Black single crystals of the compounds $\mathrm{Er}_{3} \mathrm{USe}_{8}$ and $\mathrm{Yb}_{3} \mathrm{USe}_{8}$ were first obtained by reactions of the elements in $\mathrm{NaI}$ molten flux in yields of about $50 \mathrm{wt} \%$ (based on $\mathrm{U}$ ) during our exploration of the ternary Ln-U-Se system. These compounds were synthesized in about the same yields from stoichiometric reactions of the elements in the NaI molten flux using the same temperature profile. No further attempts were made to maximize the yields. The relatively small black crystals of these compounds could not be separated from the black crystalline secondary byproducts UOSe and $\mathrm{Ln}_{2} \mathrm{Se}_{3}$. Thus, the magnetic properties of these compounds were not investigated.

\subsection{Crystal structures}

$\mathrm{Er}_{3} \mathrm{USe}_{8}$ and $\mathrm{Yb}_{3} \mathrm{USe}_{8}$. These two isostructural compounds crystallize in a new structure type with one formula unit in space group $D_{2}^{1} h-P b c m$ of the orthorhombic crystal system. A general view of crystal structure of $\mathrm{Ln}_{3} \mathrm{USe}_{8}(\mathrm{Ln}=\mathrm{Er}$ and $\mathrm{Yb})$ is shown in Fig. 1 and metrical data are presented in Tables 1 and 2 and in Supplementary information. The Ln and U atoms in this structure are disordered on the $(4 d)$ crystallographic site. The asymmetric unit of the structure comprises one Ln/U site (site symmetry ..m) and two Se sites (Se1 (..m) and Se2 (2..)). Each Ln/U 
atom is coordinated to eight Se atoms $(4 \times \operatorname{Se} 1$ and $4 \times \mathrm{Se} 2)$ in a bicapped trigonal prism (Fig. 2). This (U/Ln)Se 8 unit is connected to other neighboring $(\mathrm{U} / \mathrm{Ln}) \mathrm{Se}_{8}$ polyhedra by edge-, corner-, and face-sharing to form a three-dimensional network. The U-Se interatomic distances (2.7867(4) to $3.0248(2) \AA$ ) in these two compounds are typical for $\mathrm{U}^{4+}-\mathrm{Se}$ interactions in related compounds (Table 3). Se2 atoms in this structure form linear infinite chains running along the $c$ direction with $\mathrm{Se} 2-\mathrm{Se} 2$ interactions of $\sim 2.74 \AA$. These $\mathrm{Se} 2-\mathrm{Se} 2$ interactions are intermediate in length to an $\mathrm{Se}-\mathrm{Se}$ single bond $(\sim 2.35 \AA)$ and a van der Waals interaction. There are two Se infinite chains in the unit cell. In each the Se-Se distances are constant. The Se-Se interactions in the structures of related compounds are also presented in Table 3. Note that in these related structures the $\mathrm{Se}-\mathrm{Se}$ distances are not constant but alternate ...long-short-long... However, the average $\mathrm{Se}-\mathrm{Se}$ distances in these compounds are comparable with the corresponding distances in the $\mathrm{Ln}_{3} \mathrm{USe}_{8}$ structures (Table 3). Theoretical calculations have shown that linear infinite chains with equidistant p-block atoms are unstable [31] and hence should lead to modulated structures as are known for $\mathrm{KTh}_{2} \mathrm{Se}_{6}$ [32], $\mathrm{TlU}_{2} \mathrm{Se}_{6}$ [33], and $\mathrm{CsNp}_{2} \mathrm{Se}_{6}$ [33]. However, no modulation was observed for the present $\mathrm{Ln}_{3} \mathrm{USe}_{8}$ structures. Moreover, the displacement parameters of the Se atoms are well behaved (Supplementary information).

As discussed earlier, most LnAnSe structures either exhibit $\mathrm{Ln} / \mathrm{An}$ disorder or are ordered variants of known actinide or lanthanide binary structures. However, the crystal structure of $\mathrm{Ln}_{3} \mathrm{USe}_{8}$ [i.e., $\left(\operatorname{Ln}_{0.75} \mathrm{U}_{0.25}\right) \mathrm{Se}_{2}$ ] is very different from the structures of the simple binaries $\mathrm{USe}_{2}(\alpha$ and $\beta$-form $)$ [34,35] and $\mathrm{LnSe}_{2}(\mathrm{Ln}=\mathrm{Er}[36]$ and $\mathrm{Yb}$ [37]). Interestingly, the structure of $\mathrm{Ln}_{3} \mathrm{USe}_{8}$ is related to that reported for the compound $\mathrm{HfFe}_{2} \mathrm{Si}_{2}$ [38]. A comparison of these two structures is shown in Fig. 4. The $\mathrm{HfFe}_{2} \mathrm{Si}_{2}$ structure can be obtained from the $\mathrm{Ln}_{0.75} \mathrm{U}_{0.25} \mathrm{Se}_{2}$ structure by replacing $\mathrm{Hf}$ with $(\mathrm{Ln} / \mathrm{U}), \mathrm{Si}$ with $\mathrm{Se}$, and filling the empty $(4 d)$ and $(4 c)$ sites by $\mathrm{Fe}$ atoms, as shown in Fig. 4. $\mathrm{HfFe}_{2} \mathrm{Si}_{2}$ also features linear infinite chains of $\mathrm{Si}$ atoms.

The structures of the ternary $\mathrm{Ln}_{2} \mathrm{USe}_{5}[10,11]$ family of compounds in the $\mathrm{Ln} / \mathrm{U} / \mathrm{Se}$ system are derived from the $\mathrm{U}_{3} \mathrm{~S}_{5}$ [i.e., $\left(\mathrm{U}^{3+}\right)_{2} \mathrm{U}^{4+}\left(\mathrm{S}^{2-}\right)_{5}[14]$ structure by replacing the two $\mathrm{U}^{3+}$ ions by two $\mathrm{Ln}^{3+}$ ions. Only one compound, namely $\mathrm{La}_{2} \mathrm{U}_{2} \mathrm{Se}_{9}$ [21], is known among $\mathrm{Ln} / \mathrm{An} / \mathrm{Q}$ compounds where the $\mathrm{Ln}$ and An atoms are ordered and form a completely new structure type. In contrast to 
the structure of $\mathrm{Ln}_{3} \mathrm{USe}_{8}$, the $\mathrm{La}_{2} \mathrm{U}_{2} \mathrm{Se}_{9}$ [21] structure contains nine-coordinate $\mathrm{U}$ atoms and eightand ten-coordinated La atom and three distinct types of linear infinite Se chains with alternating Se-Se distances (2.712(3), 2.748(3); 2.803(3), 2.807(3); 2.796(3), 2.814(3) $\AA$ ).

\subsection{Oxidation states}

The presence of $\mathrm{Se}-\mathrm{Se}-\mathrm{Se}$ chains in $\mathrm{Ln}_{3} \mathrm{USe}_{8}$ with intermediate interactions makes the assignment of oxidation states arbitrary. One way of achieving charge balance in $\mathrm{Ln}_{3} \mathrm{USe}_{8}$ is $3 \times$ $\mathrm{Ln}^{3+}, 1 \times \mathrm{U}^{4+}$, and $4 \times \mathrm{Se}^{2-}$. This assignment leads to an average charge of $-1.25 \mathrm{e}^{-}$on each of the remaining four Se atoms involved in the formation of the linear Se chains. Thus these Se atoms are reduced as compared with those in the $\mathrm{Se}-\mathrm{Se}$ single-bonded $\mathrm{Se}_{2}^{2-}$ dimers. This can be understood by imagining a $\mathrm{U}_{4} \mathrm{Se}_{8}$ [i.e., $\mathrm{USe}_{2}$ ] compound with the same structure as $\mathrm{Ln}_{3} \mathrm{USe}_{8}$ but without short Se-Se single bonds. This compound can be charge balanced as $4 \times \mathrm{U}^{4+}$ and $8 \times$ $\mathrm{Se}^{2-}$. Aliovalent substitution of $\mathrm{Ln}^{3+}$ for $\mathrm{U}^{4+}$ in this imaginary compound will lead to oxidation. Thus stability of the structure depends on the redox tendencies of $\mathrm{U}^{4+}$ to $\mathrm{U}^{4+} / \mathrm{U}^{5+}$ or $\mathrm{Se}^{2-}$ to $\mathrm{Se}^{(2-)+}$ ${ }^{x}$. In eight coordination the ionic radius of $\mathrm{U}^{5+}$ of about $0.89 \AA$ is significantly smaller than that of $\mathrm{Er}^{3+}(1.004 \AA)$ or $\mathrm{Yb}^{3+}(0.985 \AA)$ and thus oxidation of $\mathrm{U}^{4+}$ to $\mathrm{U}^{5+}$ is not favorable for the stability of this structure as both $\mathrm{Ln}$ and $\mathrm{U}$ occupy the same site. Thus oxidation of $\mathrm{Se}^{2-}$ to form the linear Se chains with intermediate distances is one way to stabilize this structure type. There are many examples of actinide chalcogenides containing infinite linear $\mathrm{Q}$ chains where average charge on $\mathrm{Q}$ is non-integer and intermediate to that of -1 in $\mathrm{Se}_{2}{ }^{2-}$ and -2 in $\mathrm{Se}^{2-}$. For example, the $\mathrm{ATh}_{2} \mathrm{Se}_{6}$ $(\mathrm{A}=\mathrm{K}$ and $\mathrm{Rb})$ compounds [32] also feature linear Se chains with an average charge of -1.25 $\mathrm{e}^{-}$on each Se atom.

\subsection{Resistivity studies}

Fig. 4 shows that $\mathrm{Er}_{3} \mathrm{USe}_{8}$ and $\mathrm{Yb}_{3} \mathrm{USe}_{8}$ are semiconductors. Their resistivities at $298 \mathrm{~K}$ of about 16 ohm.cm for $\mathrm{Er}_{3} \mathrm{USe}_{8}$ and $1000 \mathrm{ohm} . \mathrm{cm}$ for $\mathrm{Yb}_{3} \mathrm{USe}_{8}$ decrease at $500 \mathrm{~K}$ to about 10 ohm.cm and $100 \mathrm{ohm} . \mathrm{cm}$, respectively. The activation energy estimated by the Arrhenius plot (Fig. 5) is $0.17(1) \mathrm{eV}$ for $\mathrm{Yb}_{3} \mathrm{USe}_{8}$. The Arrhenius plot for $\mathrm{Er}_{3} \mathrm{USe}_{8}$ (Fig. 5) is not linear 
suggesting a complex thermal activation of carriers with activation energies between $0.02(1) \mathrm{eV}$ and $0.08(1) \mathrm{eV}$.

\section{Conclusions}

Two new ternary lanthanide (Ln) uranium selenides, $\mathrm{Er}_{3} \mathrm{USe}_{8}$ and $\mathrm{Yb}_{3} \mathrm{USe}_{8}$, were synthesized at $1198 \mathrm{~K}$ in a NaI flux. These isostructural compounds crystallize in a new structure type in space group $D_{2 h}^{11}-\mathrm{Pbcm}$ of the orthorhombic system. Though their structure shows $\mathrm{Ln} / \mathrm{U}$ disorder it is not a variant of a known binary structure. The crystal structure consists of one Ln/U site and two Se sites. Each $\mathrm{Ln} / \mathrm{U}$ atom in this structure is connected to four Se1 and four Se2 atoms to form a $(\mathrm{Ln} / \mathrm{U}) \mathrm{Se}_{8}$ polyhedron with bicapped trigonal-prismatic geometry. A threedimensional network structure is formed by face-, edge-, and corner-sharing of these (Ln/U)Se 8 units. Se 2 atoms in these structures are connected to each other to form infinite one-dimensional chains along the $c$ axis. In these chains, the two Se atoms are separated by a distance intermediate to those of a Se-Se single bond and a van der Waals interaction. One way of achieving charge balance in $\mathrm{Ln}_{3} \mathrm{USe}_{8}$ is $3 \times \mathrm{Ln}^{3+}, 1 \times \mathrm{U}^{4+}$, and $4 \times \mathrm{Se}^{2-}$. This assignment leads to an average charge of $-1.25 \mathrm{e}^{-}$on each of the remaining four Se atoms involved in the formation of these linear Se chains. Temperature-dependent resistivity measurements show that these compounds are semiconductors with activation energies of $0.02(1)$ to $0.08(1) \mathrm{eV}\left(\mathrm{Er}_{3} \mathrm{USe}_{8}\right)$ and $0.17(1) \mathrm{eV}$ $\left(\mathrm{Yb}_{3} \mathrm{USe}_{8}\right)$.

\section{Acknowledgments}

Use was made of the IMSERC X-ray Facility at Northwestern University, supported by the International Institute of Nanotechnology (IIN). C.D.M. was supported by the U.S. Department of Energy, Office of Basic Energy Sciences, under Contract No. DE-AC02$06 \mathrm{CH} 11357$. 


\section{Appendix A. Supplementary information}

Supplementary data associated with this article can be found in the online version at http://dx.doi.org.........Crystallographic data in cif format for $\mathrm{Er}_{3} \mathrm{USe}_{8}$ and $\mathrm{Yb}_{3} \mathrm{USe}_{3}$ have been deposited with FIZ Karlsruhe as CSD numbers 430143 and 430144, respectively. These data may be obtained free of charge by contacting FIZ Karlsruhe at +497247808666 (fax) or crysdata@ fizkarlsruhe.de (email). 


\section{References}

[1] F.W. Lewis, L.M. Harwood, M.J. Hudson, M.G.B. Drew, J.F. Desreux, G. Vidick, N. Bouslimani, G. Modolo, A. Wilden, M. Sypula, T.-H. Vu, J.-P. Simonin, J. Am. Chem. Soc. 133 (2011) 13093-13102.

[2] A.V. Gelis, G.J. Lumetta, Ind. Eng. Chem. Res. 53 (2014) 1624-1631.

[3] Z. Kolarik, Chem. Rev. 108 (2008) 4208-4252.

[4] G. Brauer, H. Gradinger, Z. Anorg. Allg. Chem. 276 (1954) 209-226.

[5] P. Ettmayer, J. Waldhart, A. Vendl, Monatsh. Chem. 110 (1979) 1109-1112.

[6] P. Demoncy, P. Khodadad, Ann. Chim. (Paris) 5 (1970) 341-356.

[7] R. Troc, Physica B+C 102 (1980) 233-236.

[8] V.K. Slovyanskikh, N.T. Kuznetsov, Russ. J. Inorg. Chem. (Transl. of Zh. Neorg. Khim.) 35 (1990) 447. 
[9] V.K. Slovyanskikh, N.T. Kuznetsov, N.V. Gracheva, V.G. Kipiani, Russ. J. Inorg. Chem. (Transl. of Zh. Neorg. Khim.) 30 (1985) 1720-1721.

[10] V.K. Slovyanskikh, N.T. Kuznetsov, N.V. Gracheva, Russ. J. Inorg. Chem. (Transl. of Zh. Neorg. Khim.) 29 (1984) 960-961.

[11] H. Noël, J. Prigent, Physica B+C 102 (1980) 372-379.

[12] V. Tien, M. Guittard, J. Flahaut, N. Rodier, Mater. Res. Bull. 10 (1975) 547-554.

[13] Y. Hinatsu, N. Masaki, T. Fujino, J. Solid State Chem. 73 (1988) 567-571.

[14] M. Potel, R. Brochu, J. Padiou, D. Grandjean, C. R. Seances Acad. Sci., Ser. C 275 (1972) 1419-1421.

[15] N.C. Baenziger, H.A. Eick, H.S. Schuldt, L. Eyring, J. Am. Chem. Soc. 83 (1961) 22192223.

[16] A.B. Pobedina, A.B. Ilyukhin, Russ. J. Inorg. Chem. (Transl. of Zh. Neorg. Khim.) 42 (1997) 1006-1010. 
[17] P. Piret, M. Deliens, J. Piret-Meunier, Bull. Soc. Fr. Mineral. Cristallogr. 111 (1988) 443449.

[18] E.P. Samokhvalova, V.N. Molchanov, I.V. Tat'yanina, E.A. Torchenkova, Sov. J. Coord. Chem. (Engl. Transl.) 16 (1990) 683-687.

[19] G. Henche, K. Fiedler, R. Gruehn, Z. Anorg. Allg. Chem. 619 (1993) 77-87.

[20] H.P. Beck, F. Kühn, Z. Anorg. Allg. Chem. 621 (1995) 1659-1662.

[21] D.E. Bugaris, R. Copping, T. Tyliszczak, D.K. Shuh, J.A. Ibers, Inorg. Chem. 49 (2010) 2568-2575.

[22] D.E. Bugaris, J.A. Ibers, J. Solid State Chem. 181 (2008) 3189-3193.

[23] A.J.K. Haneveld, F. Jellinek, J. Less-Common Met. 18 (1969) 123-129.

[24] C.M. Fang, A. Meetsma, G.A. Wiegers, J. Alloys Compd. 218 (1995) 224-227.

[25] M.F. Mansuetto, S. Jobic, H.P. Ng, J.A. Ibers, Acta Crystallogr. Sect. C: Cryst. Struct. Commun. 49 (1993) 1584-1585. 
[26] N.W. Tideswell, F.H. Kruse, J.D. McCullough, Acta Cryst. 10 (1957) 99-102.

[27] Bruker APEX2 Version 2009.5-1 Data Collection and Processing Software, Bruker Analytical X-Ray Instruments, Inc., Madison, WI, USA, 2009.

[28] G.M. Sheldrick, SADABS, 2008. Department of Structural Chemistry, University of Göttingen, Göttingen, Germany

[29] G.M. Sheldrick, Acta Crystallogr. Sect. A: Found. Crystallogr. 64 (2008) 112-122.

[30] R.D. Shannon, Acta Crystallogr. Sect. A: Cryst. Phys. Diffr. Theor. Gen. Crystallogr. 32 (1976) 751-767.

[31] G.A. Papoian, R. Hoffmann, Angew. Chem., Int. Ed. Engl. 39 (2000) 2408-2448.

[32] K.-S. Choi, R. Patschke, S.J.L. Billinge, M.J. Waner, M. Dantus, M.G. Kanatzidis, J. Am. Chem. Soc. 120 (1998) 10706-10714.

[33] D.E. Bugaris, D.M. Wells, J. Yao, S. Skanthakumar, R.G. Haire, L. Soderholm, J.A. Ibers, Inorg. Chem. 49 (2010) 8381-8388. 
[34] H.P. Beck, W. Dausch, J. Solid State Chem. 80 (1989) 32-39.

[35] H. Noël, M. Potel, R. Troc, L. Shlyk, J. Solid State Chem. 126 (1996) 22-26.

[36] R. Wang, H. Steinfink, Inorg. Chem. 6 (1967) 1685-1692.

[37] A.W. Webb, H.T. Hall, Inorg. Chem. 9 (1970) 843-847.

[38] Y.P. Yarmolyuk, L.A. Lysenko, E.I. Gladyshevskii, Kristallografiya 21 (1976) 829-831.

[39] A. Daoudi, M. Lamire, J.C. Levet, H. Noël, J. Solid State Chem. 123 (1996) 331-336.

[40] I. Ijjaali, K. Mitchell, F.Q. Huang, J.A. Ibers, J. Solid State Chem. 177 (2004) 257-261.

[41] B.C. Chan, Z. Hulvey, K.D. Abney, P.K. Dorhout, Inorg. Chem. 43 (2004) 2453-2455.

[42] H. Mizoguchi, D. Gray, F.Q. Huang, J.A. Ibers, Inorg. Chem. 45 (2006) 3307-3311.

[43] A. Daoudi, H. Noël, J. Alloys Compd. 233 (1996) 169-173. 
[44] J. Prakash, M.S. Tarasenko, A. Mesbah, S. Lebègue, C.D. Malliakas, J.A. Ibers, Inorg. Chem. 53 (2014) 11626-11632. 
Table 1. Crystallographic data and structure refinement details for $\mathrm{Er}_{3} \mathrm{USe}_{8}$ and $\mathrm{Yb}_{3} \mathrm{USe}_{8}{ }^{\mathrm{a}}$

\begin{tabular}{|c|c|c|}
\hline & $\mathrm{Er}_{3} \mathrm{USe}_{8}$ & $\mathrm{Yb}_{3} \mathrm{USe}_{8}$ \\
\hline$a(\AA)$ & $7.0360(2)$ & $6.9937(2)$ \\
\hline$b(\AA)$ & $7.5483(2)$ & $7.4807(2)$ \\
\hline$c(\AA)$ & $5.4672(1)$ & $5.4967(2)$ \\
\hline$V\left(\AA^{3}\right)$ & $290.36(1)$ & $287.58(2)$ \\
\hline$\rho\left(\mathrm{g} \mathrm{cm}^{-3}\right)$ & 7.843 & 8.019 \\
\hline$\mu\left(\mathrm{mm}^{-1}\right)$ & 60.366 & 63.455 \\
\hline$R(F)^{\mathrm{b}}$ & 0.009 & 0.013 \\
\hline$R_{\mathrm{w}}\left(F_{\mathrm{o}}^{2}\right)^{\mathrm{c}}$ & 0.021 & 0.032 \\
\hline \multicolumn{3}{|c|}{$\overline{\mathrm{a}} \lambda=0.71073 \AA, Z=1, T=100(2) \mathrm{K}$, space group $D_{2 h}^{11}-\mathrm{Pbcm}$. } \\
\hline \multicolumn{3}{|c|}{${ }^{\mathrm{b}} R(F)=\Sigma|| F_{\mathrm{o}}|-| F_{\mathrm{c}}|| / \Sigma\left|F_{\mathrm{o}}\right|$ for $F_{\mathrm{o}}^{2}>2 \sigma\left(F_{\mathrm{o}}^{2}\right)$} \\
\hline
\end{tabular}


Table 2. Selected interatomic lengths $(\AA)$ for $\mathrm{Er}_{3} \mathrm{USe}_{8}$ and $\mathrm{Yb}_{3} \mathrm{USe}_{8}$.

\begin{tabular}{|c|c|c|}
\hline \multirow{3}{*}{$\mathrm{Ln} / \mathrm{U} 1-\mathrm{Se} 1$} & $\mathrm{Er}_{3} \mathrm{USe}_{8}{ }^{\mathrm{a}}$ & $\mathrm{Yb}_{3} \mathrm{USe}_{8}{ }^{\mathrm{a}}$ \\
\hline & $2.8016(3) \times 1$ & $2.7867(4) \times 1$ \\
\hline & $2.8075(3) \times 1$ & $2.8018(4) \times 1$ \\
\hline \multirow{3}{*}{$\mathrm{Ln} / \mathrm{U} 1-\mathrm{Se} 2$} & $2.8952(1) \times 2$ & $2.9105(2) \times 2$ \\
\hline & $2.9738(1) \times 2$ & $2.9498(2) \times 2$ \\
\hline & $3.0248(2) \times 2$ & $3.0036(3) \times 2$ \\
\hline $\mathrm{Se} 2 \cdot \bullet \cdot \mathrm{Se} 2$ & $2.7336(1) \times 2$ & $2.7484(1) \times 2$ \\
\hline $\mathrm{U} 1 / \mathrm{Ln} 1 \bullet \bullet U \mathrm{U} 1 / \mathrm{Ln} 1$ & $4.0163(2) \times 2$ & $4.0098(2) \times 2$ \\
\hline
\end{tabular}

${ }^{\mathrm{a}} \mathrm{Both}$ Er or $\mathrm{Yb}$ and U occupy same crystallographic site $(4 d)$. 
Table 3: $U-\mathrm{Se}$ and $\mathrm{Se}-\mathrm{Se}$ interactions $(\AA)$ in some related compounds

\begin{tabular}{|c|c|c|c|c|}
\hline Compound & Structure $^{\mathrm{a}}$ & $\mathrm{U}-\mathrm{Se}^{\mathrm{b}}$ & $\mathrm{Se}-\mathrm{Se}$ & Reference \\
\hline $\mathrm{Er}_{3} \mathrm{USe}_{8}$ & $3 \mathrm{D}$ & $2.802(1)-3.025(1)$ & $2.734(1)$ & this work \\
\hline $\mathrm{Yb}_{3} \mathrm{USe}_{8}$ & $3 \mathrm{D}$ & $2.787(1)-3.004(1)$ & $2.748(1)$ & this work \\
\hline $\mathrm{Cu}_{2} \mathrm{U}_{3} \mathrm{Se}_{7}$ & $3 \mathrm{D}$ & $2.766(1)-3.212(1)$ & - & [39] \\
\hline $\mathrm{MnUSe}_{3}$ & $3 \mathrm{D}$ & $2.850(2)-3.126(3)$ & - & {$[40]$} \\
\hline $\mathrm{CsU}_{2} \mathrm{Se}_{6}$ & Layered & $2.895(1)-2.960(1)$ & $2.665(1), 2.894(1)$ & {$[41]$} \\
\hline $\mathrm{KU}_{2} \mathrm{Se}_{6}$ & Layered & $2.888(1)-2.965(1)$ & $2.703(1), 2.855(1)$ & {$[42]$} \\
\hline $\mathrm{RbU}_{2} \mathrm{Se}_{6}$ & Layered & $2.891(1)-2.961(1)$ & $2.698(1), 2.854(1)$ & {$[33]$} \\
\hline $\mathrm{TlU}_{2} \mathrm{Se}_{6}$ & Layered & $2.884(1)-2.957(1)$ & $2.704(1), 2.848(1)$ & {$[33]$} \\
\hline $\mathrm{Rh}_{2} \mathrm{U}_{6} \mathrm{Se}_{15.5}$ & $3 \mathrm{D}$ & $2.866(1)-2.985(1)$ & - & {$[43]$} \\
\hline $\mathrm{BaU}_{2} \mathrm{Se}_{5}{ }^{\mathrm{a}}$ & $3 \mathrm{D}$ & $2.858(1)-3.110(1)$ & - & {$[44]$} \\
\hline $\mathrm{La}_{2} \mathrm{U}_{2} \mathrm{Se}_{9}$ & $3 \mathrm{D}$ & $2.892(1)-3.040(1)$ & $2.712(3)-2.814(3)$ & {$[21]$} \\
\hline
\end{tabular}

${ }^{\mathrm{a}} \mathrm{In} \mathrm{La}_{2} \mathrm{U}_{2} \mathrm{Se}_{9}$ each $\mathrm{U}$ atom is nine-coordinate in a monocapped square antiprism; in all the other structures each $\mathrm{U}$ atom is eight-coordinate in a bicapped trigonal prism.

${ }^{\mathrm{b}}$ Some interatomic distances have been rounded to facilitate the comparisons. 


\section{Figure Legends.}

Fig.1. Crystal structure of $\mathrm{Ln}_{3} \mathrm{USe}_{8}(\mathrm{Ln}=\mathrm{Er}, \mathrm{Yb})$ viewed along $c$ axis. Se-Se interactions are shown as thick blue lines for clarity.

Fig.2. Local coordination environment of $(L n / \mathrm{U})$ atoms in the $L_{3} \mathrm{USe}_{8}(L n=\mathrm{Er}, \mathrm{Yb})$ structure.

Fig. 3. Structural relationship between the $\mathrm{Ln}_{3} \mathrm{USe}_{8}(\mathrm{Ln}=\mathrm{Er}, \mathrm{Yb})$ and the $\mathrm{HfFe}_{2} \mathrm{Si}_{2}$ structures [38].

Fig.4. (Left) Temperature-dependent resistivities forEr $\mathrm{USe}_{8}$ single crystals showing semiconducting behavior. (Right) Arrhenius plots.

Fig.5. (Left) Temperature-dependent resistivities for $\mathrm{Yb}_{3} \mathrm{USe}_{8}$ single crystals showing semiconducting behavior. (Right) Arrhenius plots. 


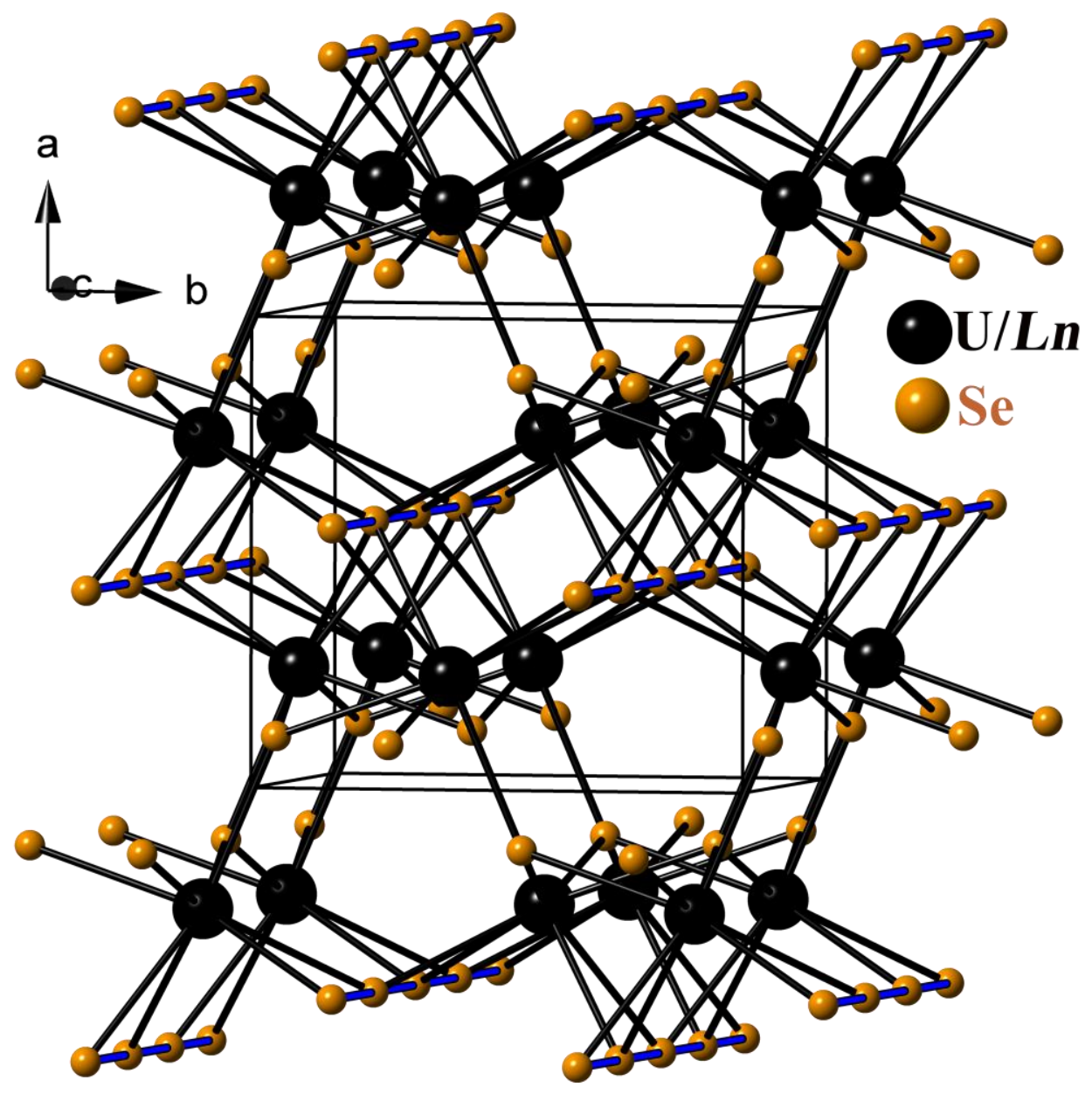




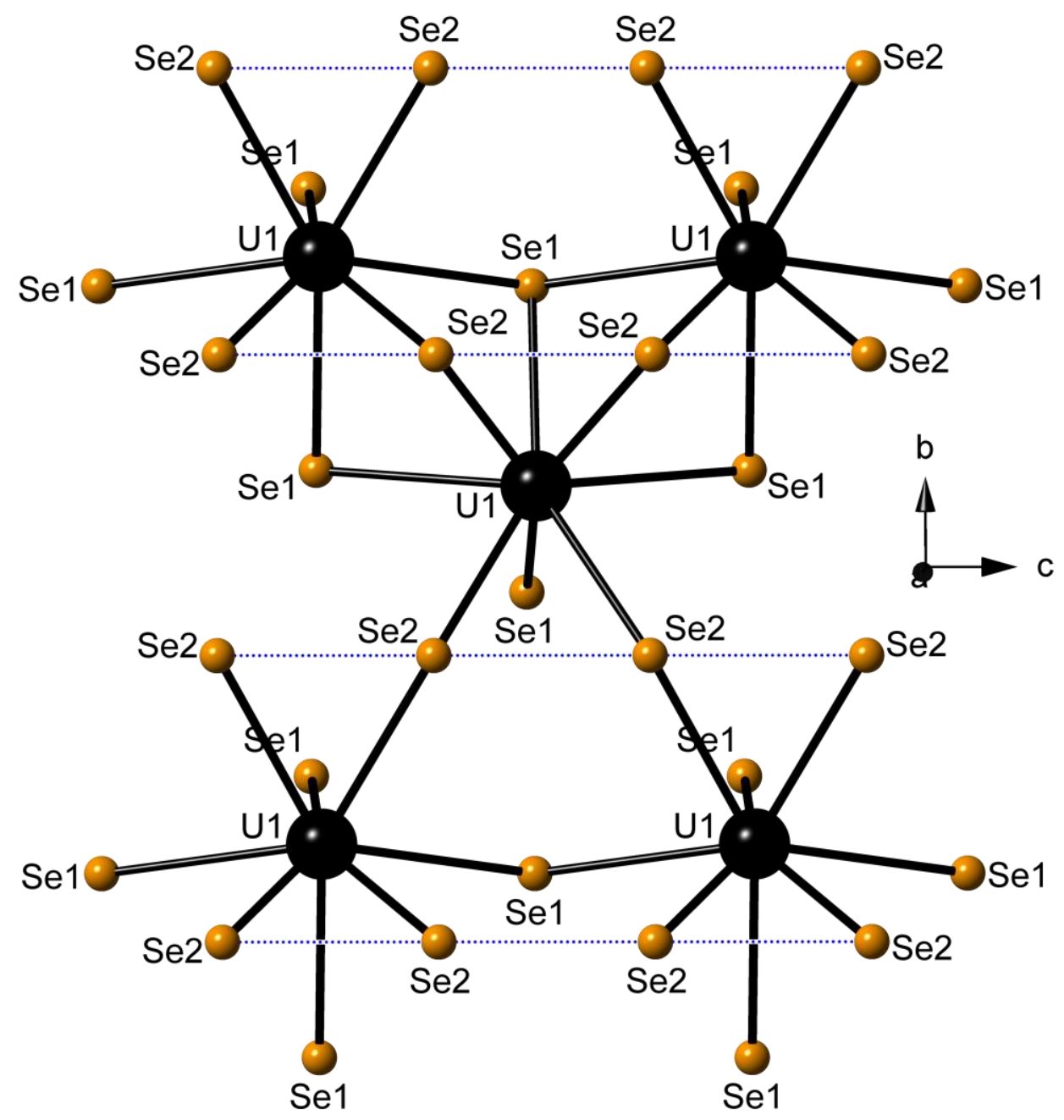




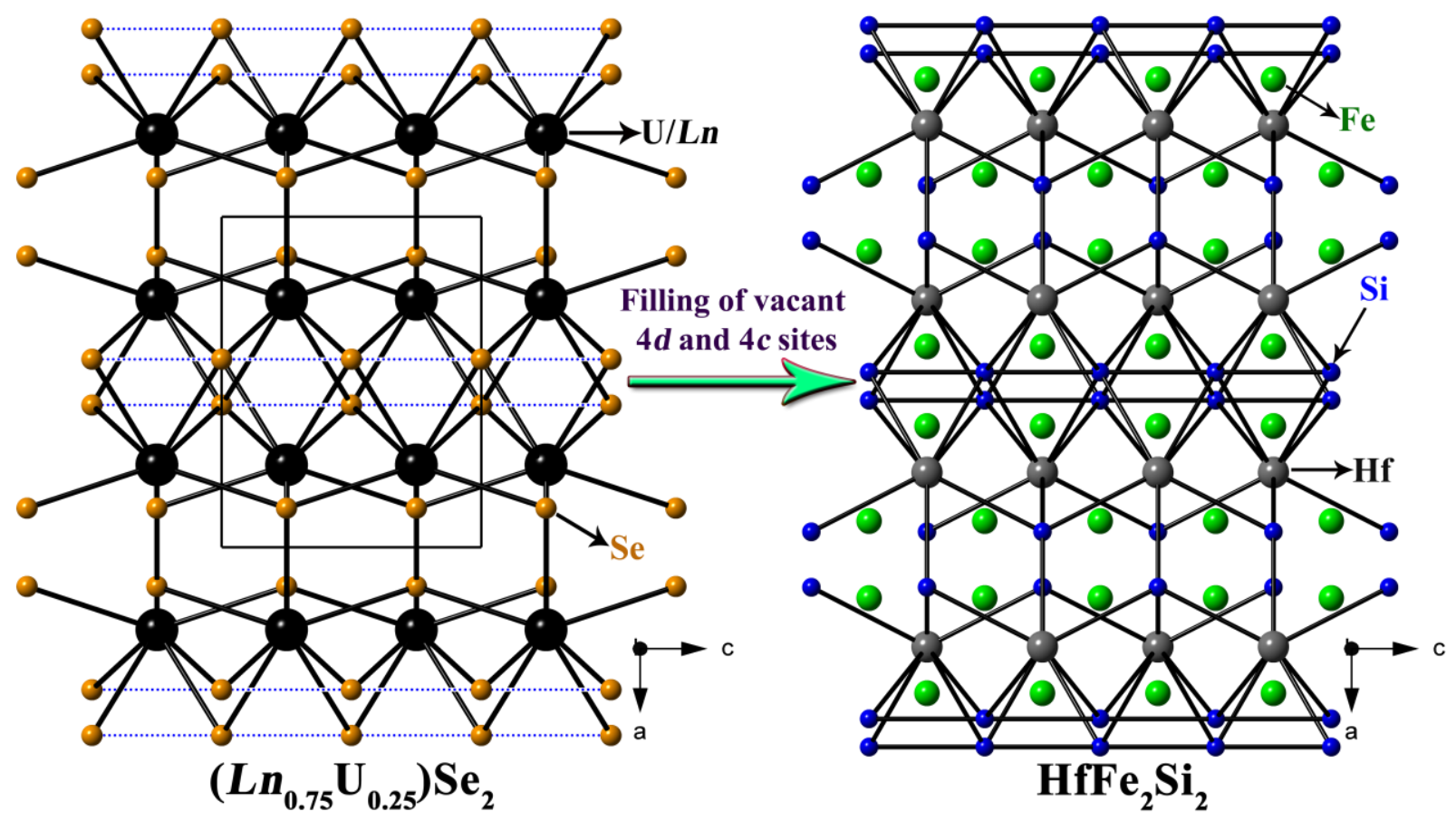



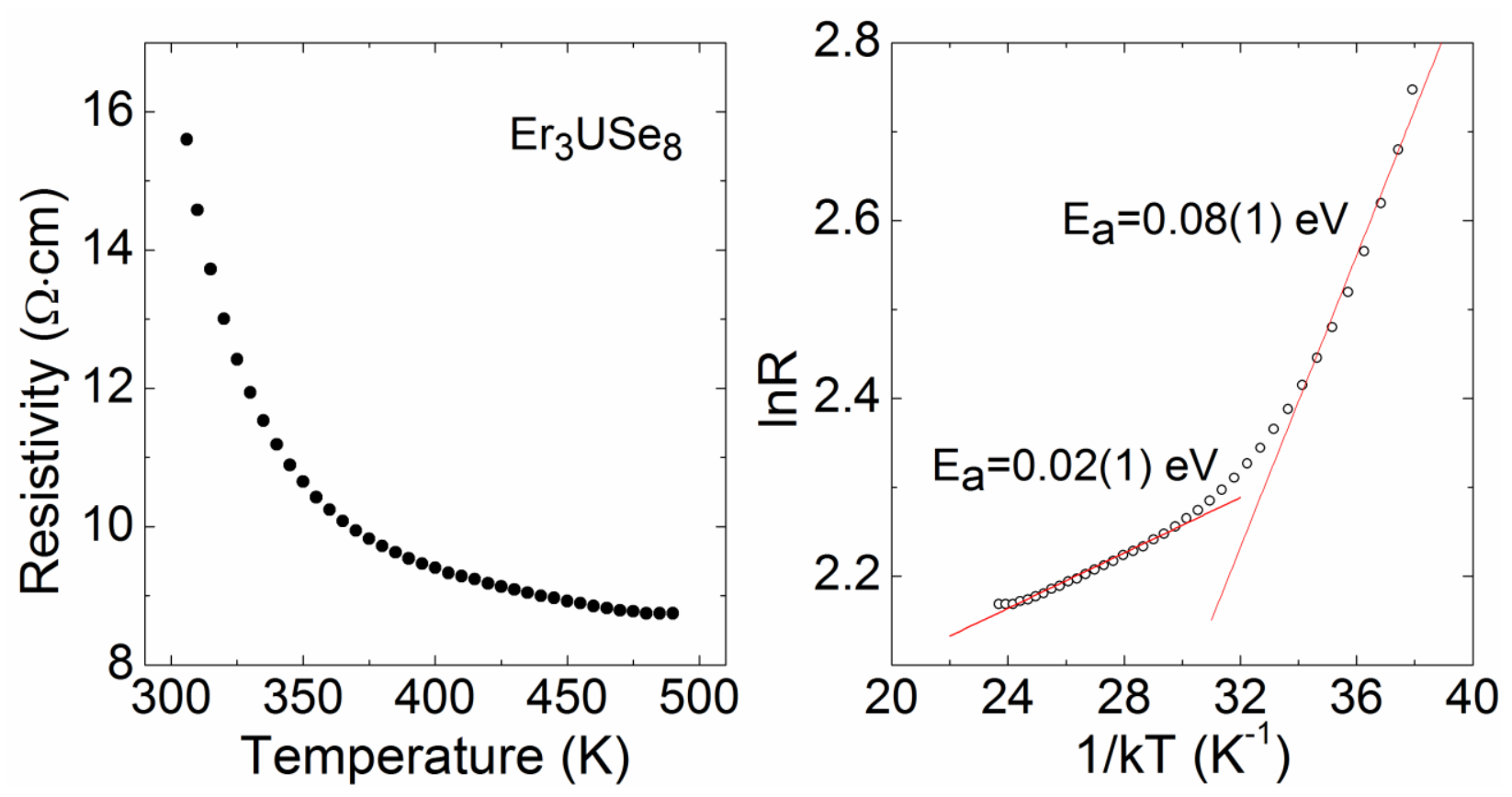

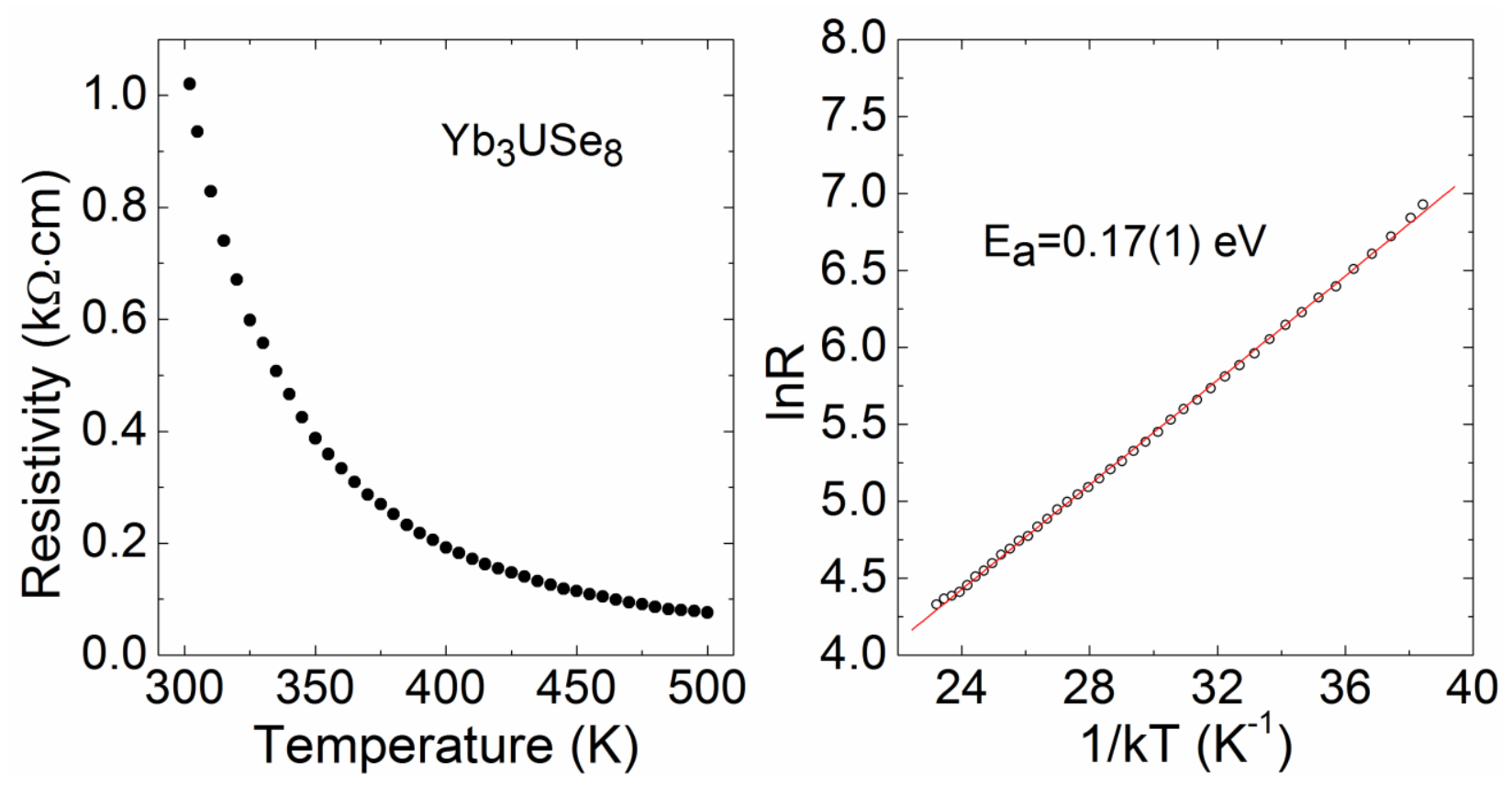


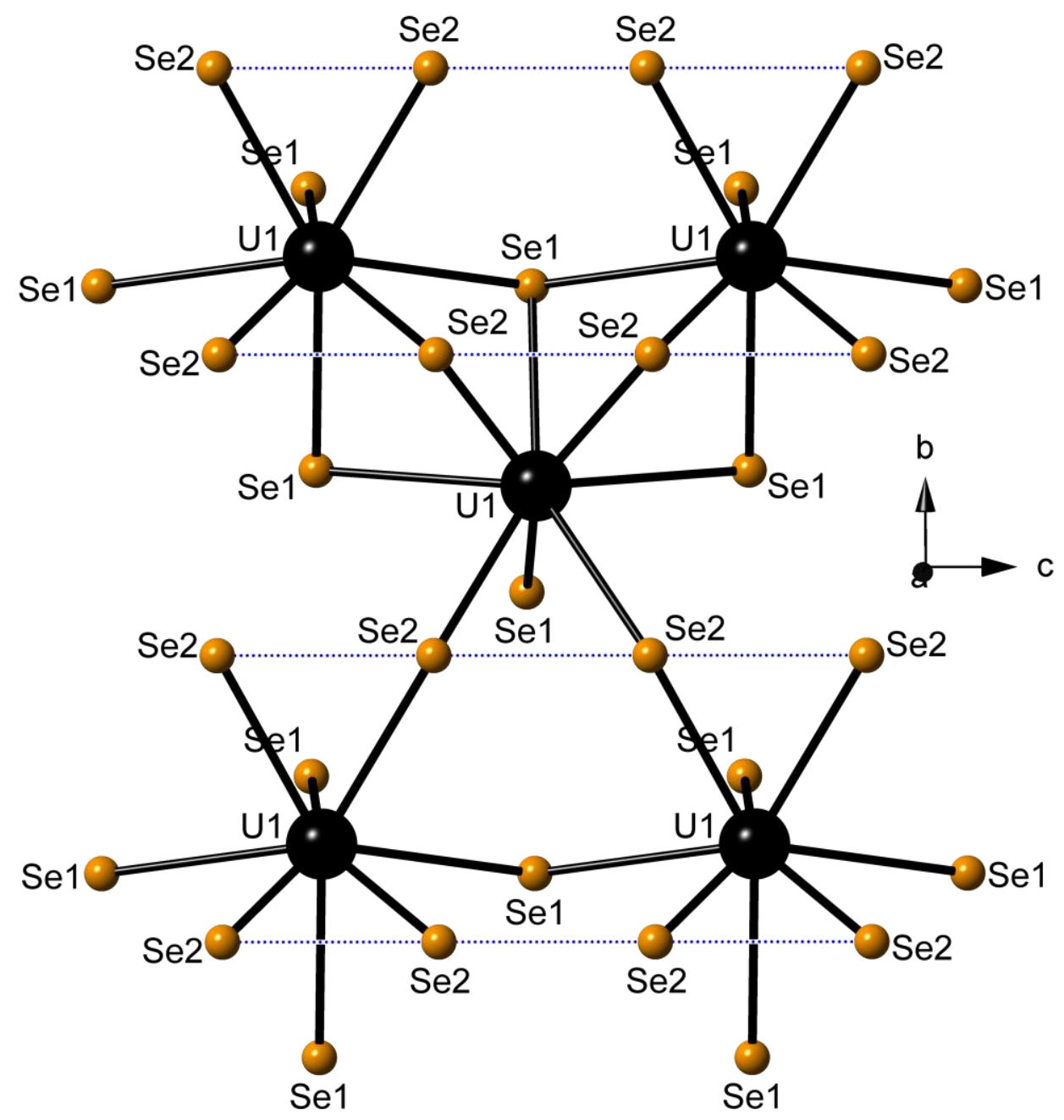


Local coordination environment of $(L n / \mathrm{U})$ atoms in the $L n_{3} \mathrm{USe}_{8}(L n=\mathrm{Er}, \mathrm{Yb})$ structure. 